\title{
Arthropod Colonisation of Trees in Fragmented Landscapes Depends on Species Traits
}

\author{
Roman Bucher ${ }^{*}, 1$ John D. Herrmann ${ }^{1}$, Christof Schüepp ${ }^{1}$, Felix Herzog ${ }^{2}$ and Martin H. Entling ${ }^{1,3}$ \\ ${ }^{I}$ University of Bern, Institute of Ecology and Evolution IEE, Baltzerstrasse 6, 3012 Bern, Switzerland \\ ${ }^{2}$ Agroscope Reckenholz-Tänikon, Research Station ART, Reckenholzstrasse 191, 8046 Zürich, Switzerland \\ ${ }^{3}$ University of Koblenz-Landau, Institute for Environmental Sciences, Fortstrasse 7, 76829 Landau, Germany
}

\begin{abstract}
Effects of habitat fragmentation vary greatly between organisms. Traits such as dispersal mode and habitat preference may explain these differences. We predict that organisms with low dispersal abilities respond mainly to habitat isolation whereas aerial colonisers respond to the amount of suitable habitats at the landscape scale. To test these predictions 30 sites were chosen that varied independently in the level of isolation from woody habitats and in the percentage of woody habitats in $500 \mathrm{~m}$ circumference. At each site seven cherry trees were established. Overwintering arthropods were sampled using cardboard hides. Glue rings were attached around tree stems to distinguish between walking and aerial colonisers. As predicted for walking dispersers, earwig abundance was strongly affected by habitat isolation. In contrast, three species of ballooning spiders responded neither to glue rings nor to habitat isolation. Instead they were affected by habitat amount in accordance with their preferred habitats. These results strongly encourage the use of species traits to predict effects of landscape fragmentation on organisms. However, additional factors such as interactions between species groups need also to be taken into account.
\end{abstract}

Keywords: Arthropods, dispersal mode, habitat fragmentation, habitat isolation, habitat amount, habitat preference, Prunus avium.

\section{INTRODUCTION}

Habitat fragmentation is a primary cause of biodiversity loss (Saunders et al. 1991, Kruess \& Tscharntke 1994, Wettstein \& Schmid 1999), but fragmentation effects on biodiversity vary greatly between studies (Debinski \& Holt 2000, Fahrig 2003). This is partly because a range of different processes are subsumed under the term habitat fragmentation (Fahrig 2003, Lindenmayer \& Fischer 2007). For example, the loss of habitat area usually has large negative effects on biodiversity, and is commonly associated with habitat fragmentation. In contrast, fragmentation per se is defined as the subdivision of a given amount of habitat into multiple patches, and can have variable effects even on related organisms (Fahrig 2003). Thus, it is important to distinguish between habitat amount and component processes of habitat fragmentation per se, such as increasing habitat isolation (Fahrig 2003). In addition, species traits such as dispersal mode and habitat preference may explain variation in the response to habitat fragmentation (Henle et al. 2004, Ewers \& Didham 2006). The identification of such trait relationships would be an important step towards a more general understanding of fragmentation effects.

Effects of habitat fragmentation on populations can be explained by metapopulation theory, which suggests higher

*Address correspondence to this author at the University of Bern, Institute of Ecology and Evolution IEE, Baltzerstrasse 6, 3012 Bern, Switzerland; Tel: 0041-31-6313032; Fax: 0041-31-6314888; E-mail: roman_bucher@students.unibe.ch extinction probabilities and reduced immigration into fragmented habitat patches (With \& King 1999a, 1999b, Hanski \& Ovaskainen 2003). The process of habitat isolation implies an increase in the distances between habitat patches. Population dynamics are differentially affected by habitat isolation according to the dispersal mode of individuals (Thomas 2000, Tscharntke et al. 2002). Organisms with low dispersal abilities should be more affected by habitat isolation, whereas highly mobile organisms may easily colonise isolated habitats if assuming all other factors to be equal. In contrast, mobile organisms with a preference for a given habitat type should respond more strongly to habitat amount in the landscape: if the amount of suitable habitats is higher in a given landscape, the overall larger population should colonise newly created habitat patches more quickly and in higher density regardless of the distance of isolation.

The aim of this study was to test effects of habitat isolation and habitat amount in the surrounding landscape on the colonisation of young cherry trees by arthropods. We expected that: (1) walking colonisers respond primarily to habitat isolation; (2) aerial colonisers are more strongly affected by landscape-scale habitat amount; and (3) responses to habitat isolation and habitat amount are restricted to species that show strong preferences for the respective habitat type.

\section{MATERIAL AND METHODS}

\section{Landscape Design}

In spring 2008, groups of young cherry trees were established at 30 sites distributed over an area of 32 by 23 
$\mathrm{km}$ north and west of the city of Berne in the Swiss plateau. Maps showing the percentage of woody habitats within a $500 \mathrm{~m}$ radius were generated in ArcGIS version 9.2 (ESRI Redlands, CA). Official land-use data (Vector25, swisstopo, Wabern) were converted into a $10 \times 10 \mathrm{~m}$ grid of either woody or other habitat types. For each grid, the percentage

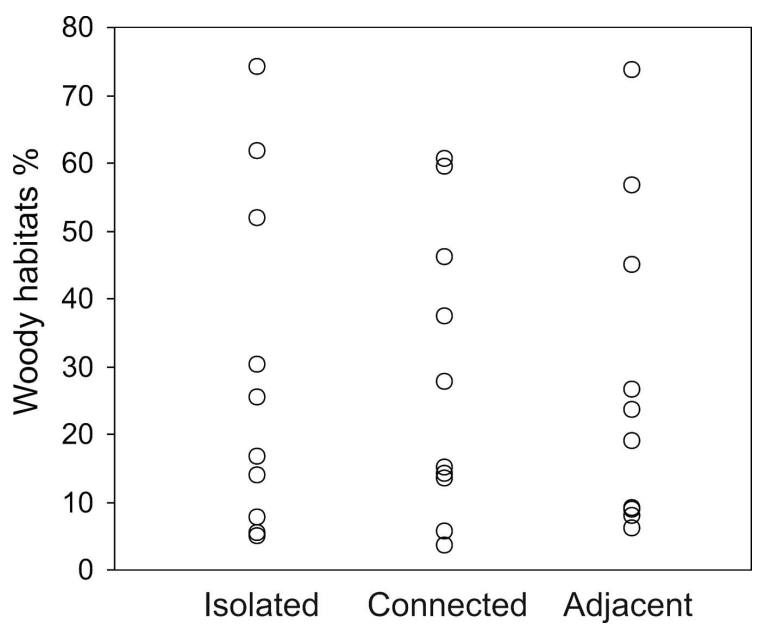

Fig. (1). Independent variation of habitat amount and isolation among the thirty study sites (Differences between means: $\mathrm{F}_{2,27}=$ $0.01, p=0.99$; Homogeneity of variances: Levene statistic $=0.10, p$ $=0.91)$.

of woody habitats was calculated within a $500 \mathrm{~m}$ radius. Using these maps, suitable sites for tree planting were located in the field that formed a gradient from low to high percentages of woody habitats in the surrounding landscapes. The sites had to be at least $750 \mathrm{~m}$ from existing sites, to avoid strong overlap between landscape sectors. Independent of the variation in the percentage of woody habitat the sites had three different levels of habitat isolation: Ten of the sites were directly adjacent to forest to represent no isolation from woody habitat. Another ten sites had no forest within $100 \mathrm{~m}$ radius but were connected to forest by hedges or single standing trees. The remaining ten sites were isolated from any woody habitat by at least $100 \mathrm{~m}$ distance through open farmland. The sites varied independently in the percentage of woody habitat in the surrounding landscape and in the degree of isolation from other woody habitats (Fig. 1; see also Farwig et al. 2009). Woody habitats were divided into forest (dense broadleaf or mixed forest) and semi-open habitats (forest edge, hedgerows, orchards, single standing trees) because some arthropods are selective between the two (Table 2). The percentage of forest within a radius of $500 \mathrm{~m}$ varied from $0.2 \%$ up to $72.0 \%$ between the 30 sites. The percentage of semi-open habitat varied between $2.2 \%$ and $6.6 \%$. The three levels of habitat isolation remained independent of habitat amount after division into forest and semi-open habitats (Forest: $\mathrm{F}_{2,27}<0.01, \mathrm{p}=0.99$; Levene statistic $=0.11, p=0.90$; Semi-open habitats: $F_{2,27}=0.71, p$ $=0.50$; Levene statistic $=0.35, \mathrm{p}=0.71)$. The percentages of forest and of semi-open habitats showed no strong correlation $(\mathrm{r}=-0.058, \mathrm{p}=0.76)$.

\section{Study Sites and Field Methods}

In March 2008, seven four-year old cherry trees (Prunus avium) were planted at each of the 30 sites. The trees were planted in a row on permanent grassland and were $3 \mathrm{~m}$ apart from each other. Before planting, arthropods overwintering on the trees were killed with winter oil (Syngenta Agro AG, 8157 Dielsdorf, Switzerland) to standardize the starting condition of tree colonisation. A glue ring ( $7 \mathrm{~cm}$ width; W. Neudorff GmbH KG, 31860 Emmerthal, Germany) was attached around the stem of three trees in each group, to prevent colonisation by walking arthropods. The glue rings were renewed three times during the study period. Hides for arthropods were attached to the stem in the canopy of all trees. They consisted of a roll of corrugated cardboard with 5 $\mathrm{cm}$ diameter and a length of $15 \mathrm{~cm}$. The top and sides were sealed with foil, and the bottom left open for entering arthropods. Arthropods use such hides as overwintering sites (Pekár 1999, Isaia et al. 2006). In late October 2008 the hides were collected and stored in a climate chamber at $5^{\circ} \mathrm{C}$. Overwintering arthropods were counted and identified to species level if possible (Table 1). We analysed five frequently observed species each with a unique combination of dispersal mode and habitat preference (Table 2).

Table 1. Spiders and Insects Observed in the Cardboard Rolls, with Numbers of Individuals and Numbers of Sites at which the Species was Found. The Frequently Observed fly Triarthria setipennis is a Parasitoid of the Earwig Forficula auricularia and was found as Pupae in the Cardboard Rolls

\begin{tabular}{|c|c|c|c|c|c|}
\hline \multirow[t]{7}{*}{ Araneae } & Anyphaenidae & Anyphaena & accentuata & 27 & 16 \\
\hline & & Larinioides & cornutus & 45 & 11 \\
\hline & & Nuctenea & umbratica & 75 & 25 \\
\hline & Dictynidae & Dictyna & arundinacea & 13 & 3 \\
\hline & & Lathys & humilis & 3 & 3 \\
\hline & Gnaphosidae & Micaria & sp. & 1 & 1 \\
\hline & Linyphiidae & Erigone & sp. & 1 & 1 \\
\hline
\end{tabular}




\begin{tabular}{|c|c|c|c|c|c|}
\hline Group & Family & Genus & Species & Individuals & Sites \\
\hline & Philodromidae & Philodromus & sp. & 51 & 23 \\
\hline & Salticidae & Heliophanus & flavipes & 1 & 1 \\
\hline & & Marpissa & muscosa & 15 & 9 \\
\hline & & Salticus & scenicus & 1 & 1 \\
\hline & Tetragnathidae & Tetragnatha & nigrita & 1 & 1 \\
\hline & Thomisidae & Diaea & dorsata & 2 & 2 \\
\hline & & Xysticus & sp. & 2 & 2 \\
\hline Blattoptera & & Ectobius & lapponicus & 1 & 1 \\
\hline \multirow{8}{*}{ Coleoptera } & & Demetrias & atricapillus & 1 & 1 \\
\hline & Chrysomelidae & Oulema & gallaeciana & 1 & 1 \\
\hline & & & melanopus & 9 & 5 \\
\hline & Coccinellidae & Coccinella & quinquepunctata & 2 & 1 \\
\hline & & & septempunctata & 34 & 12 \\
\hline & Cryptophagidae & Ephistemus & globulus & 1 & 1 \\
\hline & Curculionidae & Anthonomus & sp. & 6 & 4 \\
\hline & & Magdalis & ruficornis & 1 & 1 \\
\hline \multirow[t]{2}{*}{ Diptera } & Muscidae & Phaonia & viarum & 1 & 1 \\
\hline & Tachinidae & Triarthria & setipennis & 115 & 23 \\
\hline \multirow[t]{5}{*}{ Heteroptera } & Anthocoridae & Orius & niger & 2 & 2 \\
\hline & Lygaeidae & Gastrodes & abietum & 1 & 1 \\
\hline & & Heterogaster & urticae & 12 & 5 \\
\hline & & Rhyparochromus & pini & 1 & 1 \\
\hline & Nabidae & Himacerus & mirmicoides & 2 & 2 \\
\hline \multirow[t]{8}{*}{ Hymenoptera } & Formicidae & Myrmica & sp. & 1 & 1 \\
\hline & & Tetramorium & caespitum & 1 & 1 \\
\hline & Chalcididae & & & 8 & 6 \\
\hline & Crabronidae & Cerceris & arenaria & 1 & 1 \\
\hline & Tenthredinidae & & & 1 & 1 \\
\hline & Vespidae & Symmorphus & sp. & 1 & 1 \\
\hline & & Vespula & vulgaris & 1 & 1 \\
\hline & & Allodynerus & rossii & 2 & 1 \\
\hline Lepidoptera & Noctuidae & & & 4 & 4 \\
\hline Psocoptera & & & & 2 & 1 \\
\hline
\end{tabular}


Table 2. Dominant Mode of Dispersal and Habitat Preference of the Investigated Species (after Hänggi et al. 1995; Blandenier 2009)

\begin{tabular}{|c|c|c|}
\hline Species & $\begin{array}{c}\text { Dispersal } \\
\text { mode }\end{array}$ & Habitat preference \\
\hline \hline Forficula auricularia & Walking & Semi-open habitats and forest \\
\hline Synageles venator & Walking & Semi-open and open habitats \\
\hline Nuctenea umbratica & Ballooning & Semi-open habitats \\
\hline Larinioides cornutus & Ballooning & Semi-open and open habitats \\
\hline Anyphaena accentuata & Ballooning & Semi-open habitats and forest \\
\hline
\end{tabular}

\section{Data Analysis}

The effect of glue rings was tested by comparing the abundance of the five arthropod species between the 210 trees. To analyse effects of the landscape parameters (habitat isolation and habitat amount) on the same five species, abundances were pooled per site. Tests were done using generalized linear models with quasi-Poisson error distributions in $\mathrm{R}$ version (2.8.1) ( $\mathrm{R}$ development core team 2008). The effect of glue rings on the jumping spider Synageles venator (Lucas, 1836) was tested using Pearson's Chi-squared test, because the complete absence of the species from trees with glue rings did not allow generalized linear model calculation (Bolker et al. 2008).

\section{RESULTS}

\section{Walking Colonisers}

The common earwig Forficula auricularia (Linnaeus, 1758 ) is a walking disperser inhabiting semi-open habitats and forest (Table 2). In accordance with their walking dispersal, earwigs showed significantly higher abundances on trees without glue rings (Fig. $\mathbf{2 A} ; \mathrm{t}_{1,208}=-5.99, \mathrm{p}<0.001$ ). As expected, earwig densities were strongly affected by isolation from woody habitats (Fig. $\mathbf{2 B} ; \mathrm{t}_{3,26}=3.80, \mathrm{p}<$ $0.001)$. The response of earwigs to habitat amount was not significant (Figs. 2C, D; Forest: $\mathrm{t}_{2,27}=-0.10, \mathrm{p}=0.92$; Semiopen habitats: $\left.\mathrm{t}_{2,27}=1.18, \mathrm{p}=0.25\right)$.

The jumping spider $S$. venator is a walking disperser (Table 2), and was only found on trees without glue rings (Fig. 2E; $\chi^{2}=16$, df $\left.=1, p<0.001\right)$. In accordance with its occurrence also in open habitats (Table 2), $S$. venator showed no relation to the different levels of isolation from woody habitats (Fig. 2F; $t_{3,26}=1.28, p=0.21$ ). Neither the amount of forest (Fig. 2G; $t_{2,27}=-0.52, p=0.61$ ) nor the percentage of semi-open habitats (Fig. 2H; $\mathrm{t}_{2,27}=-0.87, \mathrm{p}=$ 0.39) had a significant effect on the abundance of this jumping spider.

\section{Aerial Colonisers}

The three remaining spider species, Nuctenea umbratica (Clerck, 1757), Larinioides cornutus (Clerck, 1757) and Anyphaena accentuata (Walckenaer, 1802), are known to disperse mostly by ballooning (Table 2 ). In accordance with their aerial dispersal they showed no significant differences in abundance between trees with and without glue rings (Figs. 2I, $\mathbf{M}$ and $\mathbf{Q} ;$ N. umbratica: $\mathrm{t}_{1,208}=1.29, \mathrm{p}=0.20 ; L$. cornutus: $\mathrm{t}_{1,208}=0.67, \mathrm{p}=0.50 ;$ A . accentuata: $\mathrm{t}_{1,208}=0.85, \mathrm{p}$ $=0.40)$. Isolation from woody habitats had no significant effect on the abundance of these spiders (Figs. 2J, $\mathbf{N}$ and $\mathbf{R}$; N. umbratica: $\mathrm{t}_{3,26}=0.88, \mathrm{p}=0.39 ;$ L. cornutus: $\mathrm{t}_{3,26}=-1.13$, $\mathrm{p}=0.27 ;$ A. accentuata: $\mathrm{t}_{3,26}=0.80, \mathrm{p}=0.43$ ).

The two orb weaving spiders $N$. umbratica and $L$. cornutus prefer semi-open habitats (Table 2). The abundance of these two spiders decreased with an increase in the percentage of forest in $500 \mathrm{~m}$ radius (Fig. 2K, O; $N$. umbratica: $\mathrm{t}_{2,27}=-2.30, \mathrm{p}=0.03 ;$ L. cornutus: $\mathrm{t}_{2,27}=-1.87, \mathrm{p}$ $=0.07) . N$. umbratica responded positively to higher amounts of semi-open habitats (Fig. 2L; $\mathrm{t}_{2,27}=2.11, \mathrm{p}=$ $0.04)$. No effect of the percentage of semi-open habitats on L. cornutus was found (Fig. $2 \mathbf{P} ; \mathrm{t}_{2,27}=-089, \mathrm{p}=0.38$ ).

The ghost spider $A$. accentuata lives in semi-open habitats and in closed forest (Table 2). In accordance with its habitat preference the abundance of this spider increased with the percentage of forest and with the percentage of semi-open habitats (Fig. 2S, T; Forest: $t_{2,27}=2.65, p=0.01$; Semi-open habitats: $\left.t_{2,27}=2.13, p=0.04\right)$.

\section{DISCUSSION}

\section{Habitat Isolation versus Habitat Amount}

Each of the five observed species showed a unique combination of dispersal mode and habitat preference. The responses to habitat isolation and/or habitat amount were also unique for each species. The earwig $F$. auricularia was the only species significantly affected by habitat isolation. This corresponds with their walking dispersal, and with their clear preference for woody habitats, which is absent in the second walking disperser, the jumping spider $S$. venator. As predicted, all three ballooning spiders did not respond to habitat isolation, but to habitat amount. Other studies on arthropods with high dispersal abilities show similar results (Krauss et al. 2003, Major et al. 2006). In accordance with our results, the majority of spiders inhabiting arable fields are known ballooners, and respond to habitat amount (Schmidt et al. 2008, Öberg et al. 2008). However, the response of spiders in the canopies of mature orchards were more variable, and included isolation effects on ballooning species (Herrmann et al. 2010). Thus, it appears that habitat age and/or trophic interactions influence species' response to habitat isolation. At the cherry tree groups of the current study, abundance and species richness of trap-nesting wasps (Hymenoptera: Crabronidae, Pompilidae and Eumeninae) were reduced by habitat isolation (Schüepp et al. 2010, see also Holzschuh et al. 2009). This contradicts the idea that flying dispersers are not sensitive to habitat isolation. However, the reduced abundance of wasps at isolated sites may be due to complications in provisioning the nests with adequate food rather than due to problems for adult wasps to reach the isolated sites. Additional studies will be necessary to assess the generality of the dichotomy between isolation effects on walking dispersers and habitat amount effects on flying dispersers, and the possible influences of additional factors such as habitat age and trophic interactions. 
Colonisation
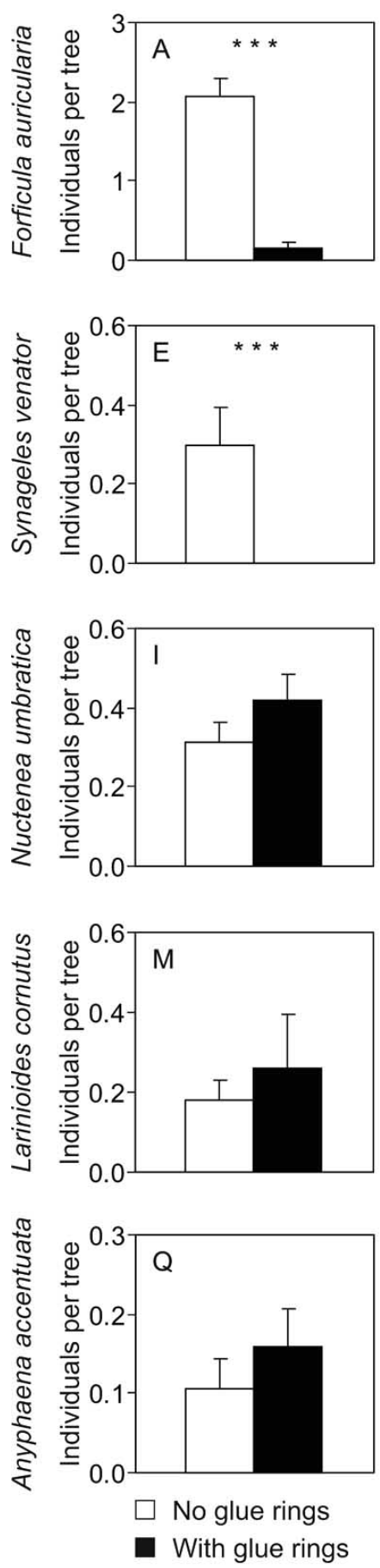

Habitat isolation
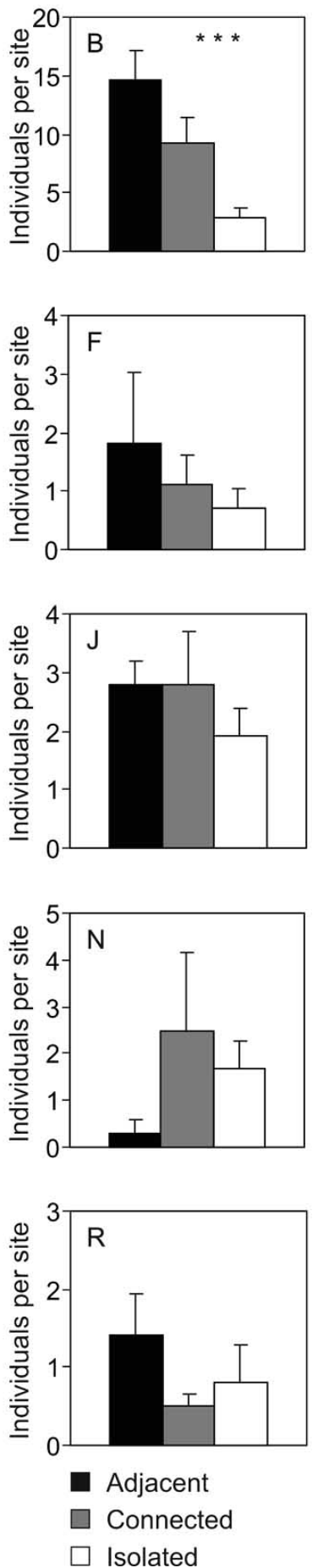
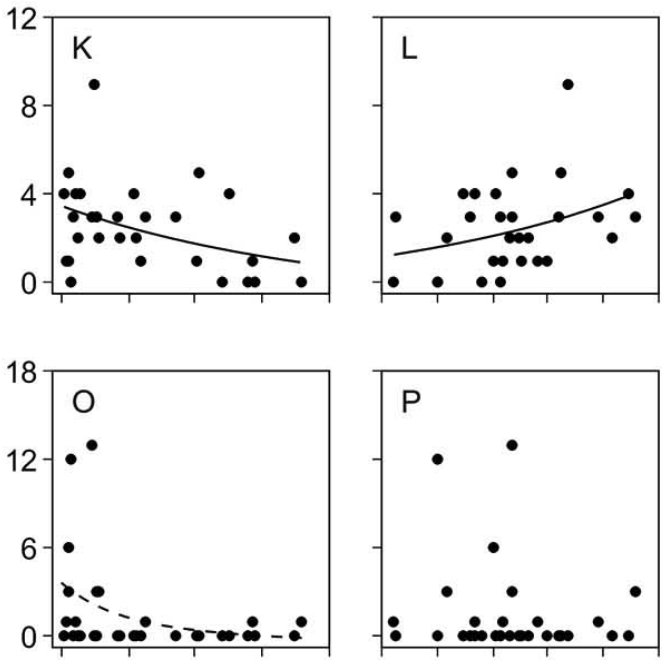

Habitat amount
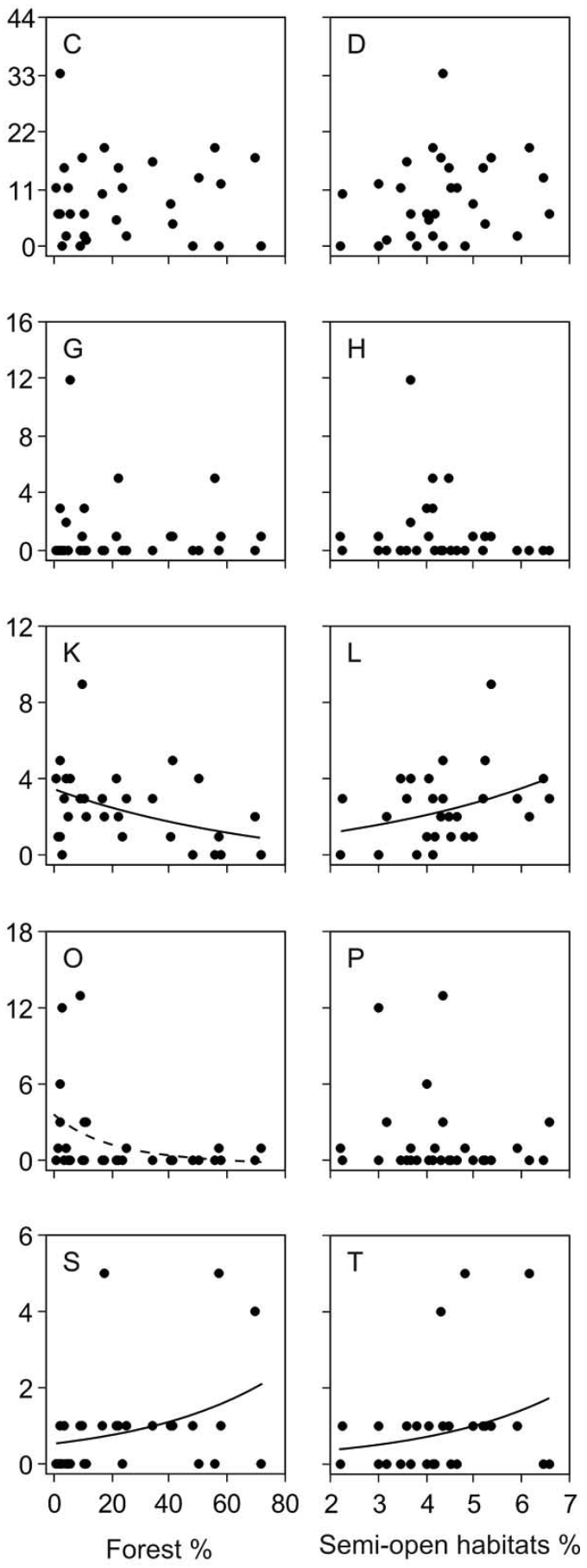

Fig. (2). Abundances of the common earwig Forficula auricularia, the jumping spider Synageles venator, the two orb weaving spiders Nuctenea umbratica and Larinioides cornutus and the ghost spider Anyphaena accentuata in relation to (A, E, I, M and Q) presence and absence of glue rings, (B, F, J, N and R) habitat isolation, (C, G, K, O and S) percentage of forest, and (D, H, L, P and T) amount of semiopen habitats $\left(* * * \mathrm{p}<0.001, * * \mathrm{p}<0.01,{ }^{*} \mathrm{p}<0.05\right)$. Continuous lines indicate significant relationships $(\mathrm{p}<0.05)$, dashed lines mark statistical trends $(\mathrm{p}<0.1)$.

\section{Habitat Preference}

With respect to habitat preference of the ballooning species, the only species that preferred closed forest responded positively to the percentage of forest in the surrounding landscape. In contrast, both species without forest preference showed the opposite, negative response to forest cover. While all three ballooning spiders are common in semi-open habitats, only $N$. umbratica and $A$. accentuata had higher densities in landscapes with high amounts of semi-open habitats. It is likely that the preference for various 
open habitats such as wetlands and fallows by L. cornutus blurred a possible influence of the (quantitatively less important) semi-open habitats. Differential effects of habitat amount according to species habitat preference are known from spiders in arable fields. While species with a strong preference for arable habitats respond negatively to the amount of perennial habitats on a landscape scale, the majority of species are generalists and respond positively to the amount of perennial habitats (Pfiffner \& Luka 2000, Schmidt et al. 2008).

\section{Colonisation Mode}

Glue rings proved to be well suited to determine the colonisation mode of arthropods, because the two species that disperse over the ground according to literature (Jacobs \& Renner 1998, Blandenier 2009) were nearly absent from trees with glue rings. Densities of ballooning spider species were not reduced by glue rings. In contrast, all three species of ballooning spiders even tended towards higher densities on trees with glue rings compared to trees without glue rings. As ballooning spiders have limited or no control over their landing location, it could have been expected that numerous individuals need to climb the trees after landing in a nearby location, which would have led to reduced densities on trees with glue rings despite flying dispersal. However, the abundance of spiders is influenced by competitors and antagonists such as ants (Wise 1993), which were largely restricted to trees without glue rings (Stutz \& Entling revised). Thus, the presence of ants may have countered a trend towards lower spider densities on trees without glue rings.

In summary, it proved highly useful to study habitat amount and isolation independently, which has rarely been done before in landscape-scale fragmentation studies (Fahrig 2003). All observed responses to habitat isolation and habitat amount were in accordance with the known biology of the species, and with theoretical predictions (Ewers \& Didham 2006). This suggests that the traits dispersal mode and habitat preference are very well suited to predict the sensitivity of species to landscape fragmentation. However, examples from the literature suggest that additional factors such as habitat age and trophic interactions can affect the response of organisms to fragmentation and require further study.

\section{ACKNOWLEDGEMENTS}

We thank Raphael Didham, Peter Hambäck and two anonymous reviewers for comments on an earlier version of the manuscript, Debra Bailey and Beatrice Schüpbach who contributed to the landscape analyses and all farmers who provided land for study sites. The study was supported by the Swiss National Science foundation under grant number 3100A0-114058 to Felix Herzog and Martin (Schmidt-) Entling.

\section{REFERENCES}

Blandenier, G (2009) Ballooning of spiders (Araneae) in Switzerland: general results from an eleven-year survey. Bulletin of the British Arachnological Society, 14, 308-16.
Bolker, BM, Brooks, ME, Clark, CJ, Geange, SW, Poulsen, JR, Stevens, MHH \& White, JS (2008) Generalized linear mixed models: a practical guide for ecology and evolution. Trends in Ecology and Evolution, 24, 127-35.

Debinski, DM \& Holt, RD (2000) A survey and overview of habitat fragmentation experiments. Conservation Biology, 14, 342-55.

Ewers, RM \& Didham, RK (2006) Confounding factors in the detection of species responses to habitat fragmentation. Biological Reviews, 81, $117-42$.

Fahrig, L (2003) Effects of habitat fragmentation on biodiversity. Annual Review of Ecology Evolution and Systematics, 34, 487-515.

Farwig, N, Bailey, D, Bochud, E, Herrmann, J, Kindler, E, Reusser, N, Schüepp, C \& Schmidt-Entling, MH (2009) Isolation from forest reduces pollination, seed predation and insect scavenging in Swiss farmland. Landscape Ecology, 24, 919-27.

Hänggi, A, Stöckli, E \& Nentwig, W (1995) Habitats of central European spiders. Miscellanea Faunistica Helvetiae, 4, 1-460.

Hanski, I \& Ovaskainen, O (2003) Metapopulation theory for fragmented landscapes. Theoretical Population Biology, 64, 119-27.

Henle, K, Davies, KF, Kleyer, M, Margules, C \& Settele, J (2004) Predictors of species sensitivity to fragmentation. Biodiversity and Conservation, 13, 207-51.

Herrmann, JD, Bailey, D, Hofer, G, Herzog, F \& Schmidt-Entling, MH (2010) Spiders associated with the meadow and tree canopies of orchards respond differently to habitat fragmentation. Landscape Ecology, 25, 1375-84

Holzschuh, A, Steffan-Dewenter, I \& Tscharntke, T (2009) Grass strip corridors in agricultural landscapes enhance nest-site colonization by solitary wasps. Ecological Applications, 19, 123-32.

Isaia, M, Bona, F \& Badino, G (2006) Comparison of polyethylene bubble wrap and corrugated cardboard traps for sampling tree-inhabiting spiders. Environmental Entomology, 35, 1654-60.

Jacobs, W \& Renner, M (1998) Biologie und Ökologie der Insekten. Gustav Fischer Verlag, Stuttgart.

Krauss, J, Steffan-Dewenter, I \& Tscharntke, T (2003) Local species immigration, extinction, and turnover of butterflies in relation to habitat area and habitat isolation. Oecologia, 137, 591-602.

Kruess, A \& Tscharntke, T (1994) Habitat fragmentation, species loss, and biological control. Science, 264, 1581-4.

Lindenmayer, DB \& Fischer, J (2007) Tackling the habitat fragmentation panchreston. Trends in Ecology and Evolution, 22, 127-32.

Major, RE, Gowing, G, Christie, FJ, Gray, M \& Colgan, D (2006) Variation in wolf spider (Araneae: Lycosidae) distribution and abundance in response to the size and shape of woodland fragments. Biological Conservation, 132, 98-108.

Öberg, S, Mayr, S \& Dauber, J (2008) Landscape effects on recolonisation patterns of spiders in arable fields. Agriculture Ecosystems \& Environment, 123, 211-8.

Pfiffner, L \& Luka, H (2000) Overwintering of arthropods in soils of arable fields and adjacent semi-natural habitats. Agriculture Ecosystems \& Environment, 78, 215-22.

Pekár, S (1999) Some observations on overwintering of spiders (Araneae) in two contrasting orchards in the Czech Republic. Agriculture Ecosystems \& Environment, 73, 205-10.

$\mathrm{R}$ development core team (2008) R: a language and environment for statistical computing. $\mathrm{R}$ foundation for statistical computing.

Saunders, DA, Hobbs, RJ \& Margules, CR (1991) Biological consequences of ecosystem fragmentation: a review. Conservation Biology, 5, 1832.

Schmidt, MH, Thies, C, Nentwig, W \& Tscharntke, T (2008) Contrasting responses of arable spiders to the landscape matrix at different spatial scales. Journal of Biogeography, 35, 157-66.

Schüepp, C, Herrmann, JD, Herzog, F \& Schmidt-Entling, MH (2010) Differential effects of habitat isolation and landscape composition on wasps, bees, and their enemies. Oecologia, DOI 10.1007/s00442-010-1746-6.

Stutz, S \& Entling, MH. Effects of the landscape context on aphid-antpredator interactions on cherry trees. Biological Control (Submitted).

Thomas, CD (2000) Dispersal and extinction in fragmented landscapes. Proceedings of the Royal Society of London, Series B, 267, 139145.

Tscharntke, T, Steffan-Dewenter, I, Kruess, A \& Thies, C (2002) Characteristics of insect populations on habitat fragments: a mini review. Ecological Research, 17, 229-39. 
Wettstein, W \& Schmid, B (1999) Conservation of arthropod diversity in montane wetlands: effect of altitude, habitat quality and habitat fragmentation on butterflies and grasshoppers. Journal of Applied Ecology, 36, 363-73.

Wise, DH (1993) Spiders in ecological webs. Cambridge University Press, Cambridge.
With, KA \& King, AW (1999a) Dispersal success on fractal landscapes: a consequence of lacunarity thresholds. Landscape Ecology, 14, 7382.

With, KA \& King, AW (1999b) Extinction thresholds for species in fractal landscapes. Conservation Biology, 11, 945-56.

Received: September 16, 2010

Revised: October 21, 2010

Accepted: October 22, 2010

(C) Bucher et al.; Licensee Bentham Open.

This is an open access article licensed under the terms of the Creative Commons Attribution Non-Commercial License (http://creativecommons.org/licenses/by$\mathrm{nc} / 3.0 /$ ), which permits unrestricted, non-commercial use, distribution \& reproduction in any medium, provided the work is properly cited. 